\title{
MONITORING LAND SUBSIDENCE EVOLUTION IN THE CENTRAL URBAN REGION OF HANOI CITY, VIETNAM
}

\author{
NGUYEN Cong Giang \\ Hanoi Architectural University; add: km 10, Nguyen Trai, Thanh Xuan, Hanoi, Vietnam

\section{DANG Vu Khac} \\ Hanoi National University of Education; add: 136, Xuan Thuy, Cau Giay, Hanoi, Vietnam

\section{VU Anh Tuan} \\ Vietnam National Space Center; add: 18, Hoang Quoc Viet, Cau Giay, Hanoi, Vietnam.
}

\begin{abstract}
Applying the persistent scatterer interferometric synthetic aperture radar (PSInSAR) approach, land subsidence in the central urban region of Hanoi city is monitored from 2007 to 2019 by using 21 ALOS-1 images acquired from February 2007 to February 2011 and 51 Sentinel-1 images acquired from April 2016 to September 2019. The average velocity maps of land subsidence in the line of sight (LOS) of the satellite show the contrast in the land subsidence of the northern and southern banks of the Red River: in the first period, the northern bank is quite stable, while some areas subside at remarkable velocities on the southern bank, where many construction works have occurred and groundwater has been strongly exploited over the past decades. The ground is deformed in three main areas: Hoang Mai, Ha DongThanh Xuan, and Nam Tu Liem-Hoai Duc. The PSInSAR results also show some small subsidence areas downtown. In the second period, the ground surface remains stable on the northern bank of the Red River, and land subsidence occurs mainly on the southern bank in comparison with that of the previous period. However, the subsidence velocity decreases and only presents two main subsidence areas in $\mathrm{Ha}$ Dong-Thanh Xuan, and Nam Tu Liem-Hoai Duc, while subsidence significantly weakens in Hoang Mai. The results obtained from the PSInSAR approach correspond to the in situ measurements taken in the period 2007-2008 by the leveling method. This correspondence indicates the ability to apply multitemporal and multi-SAR system data for monitoring land subsidence in large urban areas over a long time with high reliability and reasonable cost.
\end{abstract}

Keywords: land subsidence, urban geology, PSInSAR, leveling, Sentinel-1, ALOS-1 
Cite this Article: NGUYEN Cong Giang, DANG Vu Khac, VU Anh Tuan, Monitoring Land Subsidence Evolution in the Central Urban Region of Hanoi City, Vietnam, International Journal of Civil Engineering and Technology, 11(6), 2020, pp. 18-30.

https://iaeme.com/Home/issue/IJCIET?Volume $=11 \&$ Issue $=6$

\section{INTRODUCTION}

The phenomenon of subsidence due to groundwater exploitation is becoming increasingly common and recorded in many major cities around the world, such as Mexico-City (Waltham, 2014), Bangkok (Phien-wej et al., 2006), Shanghai (Lin et al., 2011), Venice (Brambati et al., 2003), and Jakarta (Brambati et al., 2003). Subsidence needs to be given more attention when it occurs in cities, where a strong urbanization process leads to an increase in the demand for drinking water, which is usually withdrawn from underground (Johnson 1995). The consequences are often worse if the city is located on alluvial plains composed of unconsolidated, easily compacted sedimentary formations.

Hanoi is a rapidly urbanizing city among developing countries, where groundwater is the main resource for drinking water demand due to its low cost of treatment (Jusseret et al., 2010). To date, after several adjustments of administrative boundaries, this city has 12 urban districts and 18 suburban districts (Figure 1). New districts have been established, such as Tay Ho in 1995, Thanh Xuan and Cau Giay in 1996, Long Bien and Hoang Mai in 2003, Ha Dong in 2008, and Nam Tu Liem and Bac Tu Liem in 2013. The urban space is increasingly expanding. The population of the city increased from $2,431 \times 10^{6}$ to $3,184 \times 10^{6}$ inhabitants from 1995 to 2006 , in which the population of urban districts doubled from $1,082 \times 10^{6}$ to $2,050 \times 10^{6}$ inhabitants in the same period. The population reached $7,661 \times 10^{6}$ in 2017 with a density of 2304 inhabitants $/ \mathrm{km}^{2}$ (GSO, 2018). The establishment of new urban districts around downtown Hanoi has led to the explosion in new residential areas and the accompanying expansion of groundwater withdrawal to meet the daily water requirements of inhabitants. This consequence is evidenced by the continuous construction of water plants in the period of 2002-2005, each with a capacity of approximately $30,000 \mathrm{~m}^{3} /$ day (PPJ et al., 2011).

However, since the 1990s, the lowering water table (Montangero et al., 2007) and the building of houses on soft soil (Nguyen and Helm, 1995) have been the main reasons for land subsidence. Much damage has affected the foundations of residential houses, construction works and even some high-rise old buildings. Therefore, the city has imported surface water from remote provinces to reduce the pressure on groundwater extraction because the aquifers have reached the recovery limit (Tran, 2005). Specifically, in 2008, the city built a Da River water plant with a capacity of $300,000 \mathrm{~m}^{3} /$ day, and in 2018 , the city built a Duong River water plant with a capacity of $150,000 \mathrm{~m}^{3} /$ day. In addition, since the $1990 \mathrm{~s}$, the city has monitored land subsidence with several studies. 


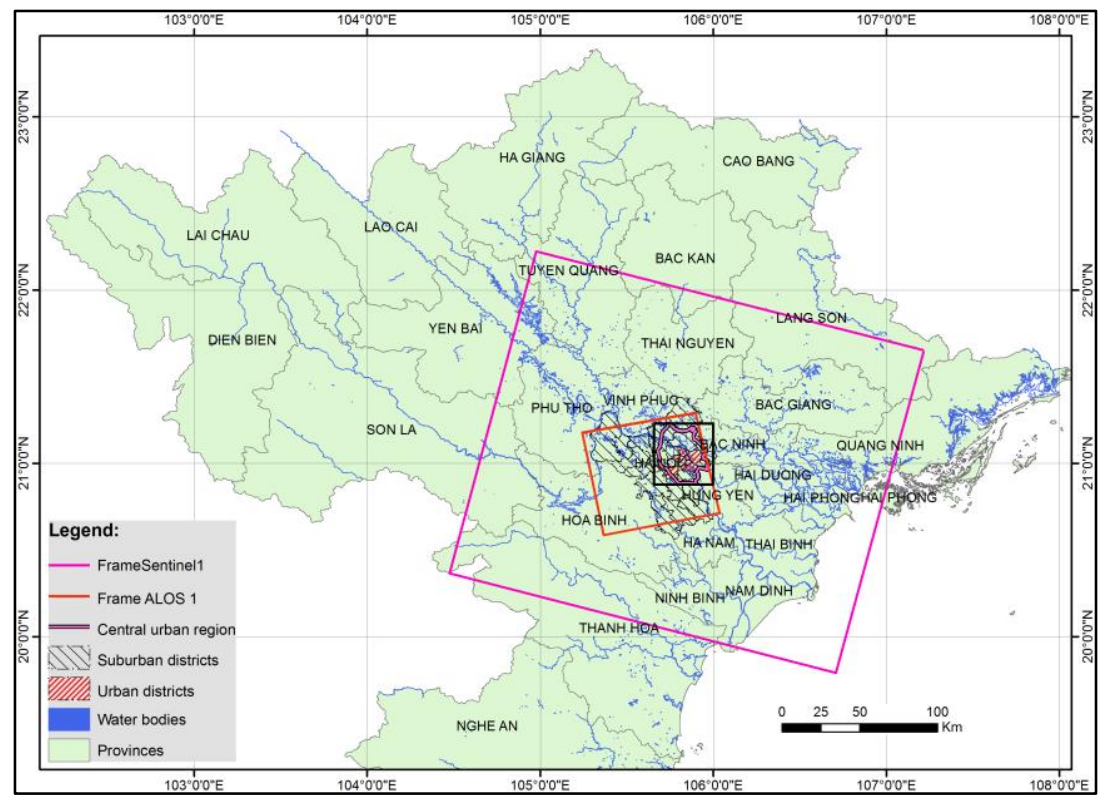

Figure 1 Central urban region of Hanoi with suburban and urban districts. Black box corresponds to the study area with InSAR processing in Figure 3

To monitor land subsidence, researchers use a variety of quantitative measurement techniques, from in situ measurements such as the leveling method (Bitelli and Russo, 1991) and the extensometer method (Poland, 1984) to space technology such as the static GPS measurement method (Ikehara, 1994), the interferometric synthetic aperture radar (InSAR) method (Massonnet and Feigl, 1998), or the aerial LiDAR method (Froese and Mei, 2008). In the case of land subsidence in Hanoi, previous studies, based on in situ measurement methods (Dinh et al., 2008; Nguyen, 2007; Nguyen and Helm, 1995) or modeling of soil geotechnical properties (Trinh and Fredlund, 2000) have obtained results showing that some areas of urban districts have been affected by land subsidence in the past few decades. Using InSAR, which has the advantage of providing information on land subsidence in large areas, several studies have focused on land subsidence in downtown areas (Carnec and Raucoules, 2001; Noel, 2008; Raucoules and Carnec, 1999; Tran, 2007; Vöge, 2011). These studies used a conventional approach of the interferometric synthetic aperture radar technique (InSAR) that suffered from some basic limitations. They did not obtain the subsidence rate of the entire "central urban region", which is defined in the "Hanoi Capital Construction Master Plan to 2030 and Vision to 2050". Therefore, by processing ALOS-1 images with the multitemporal InSAR method, Dang's research identified three main subsidence areas in the central urban region. Moreover, the results also showed that the subsidence rate has increased rapidly since 2008, after the integration of Ha Tay province into Hanoi city (Dang et al., 2013).

Recently, the new data policy and successful launch of a new series of Earth observation SAR satellites, especially Sentinel-1A (April 2014) and Sentinel-1B (April 2016), has allowed users to freely access unlimited data sources. At the same time, the land subsidence level has been changing temporally and spatially. Accordingly, continuous monitoring of land subsidence progress in the central urban region is required because of the concentration of many important constructions in the future. The results of long-term land subsidence monitoring allow the deployment of appropriately detailed planning and encourage technical solutions for safe construction in areas threatened by land subsidence. However, SAR data from a single satellite may not be available for a long time. Therefore, the multitemporal InSAR method with the PSInSAR approach has been considered for application to two sets of 
SAR data, ALOS-1 and Sentinel-1. This research uses a dataset of 22 ALOS-1 images (L band) from February 2007 to February 2011 and a dataset of 51 Sentinel-1 images (C band) from April 2016 to September 2019. The goals of this research are: 1) to monitor the spatial evolution of land subsidence from 2007 - 2011 to 2016 - 2019 and 2) to compare the change in the average velocity in the direction of satellite - LOS, especially in the main subsidence areas in the central urban region (Figure 1).

\section{METHOD AND DATA USED}

\subsection{Interferometric Synthetic Aperture Radar}

The identification of land deformation, including land subsidence, by the InSAR technique has been proven successfully for more than two decades in many areas of the world (Solari et al., 2018). The conventional InSAR method creates an interferogram corresponding to the phase difference when the study area is repeatedly captured. The phase difference value of each pixel contains several terms (Massonnet \& Feigl, 1998):

$$
\Phi=\Sigma\left(\Delta \varphi_{\text {orb }}+\Delta \varphi_{\text {topo }}+\Delta \varphi_{\text {atm }}+\Delta \varphi_{\mathrm{N}}+\Delta \varphi_{\text {def }}\right)
$$

where, $\Delta \varphi_{\text {orb }}, \Delta \varphi_{\text {topo }}, \Delta \varphi_{\text {atm }}$, and $\Delta \varphi_{\text {def }}$ are the phase differences caused by the position of the orbit, topography, atmospheric delay and land deformation, respectively. To obtain the deformation term $\Delta \varphi_{\text {def }}$ with high accuracy, a good estimation of the other terms is necessary. The terms $\Delta \varphi_{\text {orb}}$, and $\Delta \varphi_{\text {topo }}$ can be determined by precise orbital data and accurate topography. The atmospheric noise term $\Delta \varphi_{\text {atm }}$ is removed by processing the multitemporal InSAR when many SAR images of the study area are stacked simultaneously. As a result, the signal/noise ratio will be increased and allow for the determination of the average velocity during the imagery collection period (Peltzer et al., 2001). The noise term $\Delta \varphi_{N}$ is related to the variation level due to scattering, thermal noise and errors in data processing. Since this term is difficult to eliminate completely, it can be accepted as included in the errors of the InSAR method. The land deformation term $\Delta \varphi_{\text {def, }}$ accordingly, has accuracy varying from a few centimeters to a few millimeters depending on the data used and the processing method, expressed as a formula:

$\Delta \varphi_{\text {def }}=4 \pi \Delta \mathrm{R} / \lambda$

where $\Delta \mathrm{R}$ is the change in the distance between the satellite and the ground along the LOS of the satellite and $\lambda$ is the wavelength used by the radar system. Because of its high sensitivity to vertical displacement, the monitoring of land subsidence with the InSAR method has become one of the main applications for land deformation studies (Galloway et al., 1998), especially in urban areas where persistent pixels over time are very abundant (Crosetto et al., 2013).

In the case of strong land subsidence, the $\Delta \varphi_{\text {def }}$ term becomes dominant, so it is easy to determine the displacement between two successive image acquisitions (Amelung et al., 1999). However, in the case of slow motion, the estimation of the land deformation term may be limited by the prominence of other terms in equation (1). Otherwise, the estimation is also affected by the decorrelation between the pairs of synthetic aperture radar images. The decorrelation is caused by a change in the satellite view between two observations (different views), the change in the position of scatterers, or the change in geometry in the resolution cell. When decorrelation becomes important, SAR images are not suitable for creating interferograms.

A multitemporal InSAR method was developed to overcome the temporal decorrelation, which causes changes in scattering properties, to reduce the impact of the atmosphere and to measure displacement over time. This method is based on the acquisition of multiple SAR images and includes two approaches: persistent scatterers (PSInSAR) and small baseline 
(SBAS). In general, these two approaches are optimal for handling scatterers on the ground. The PSInSAR approach aims to handle prominent resolution cells by a single scatterer, while the SBAS approach aims to deal with resolution cells without a prominent scatterer. In this study, the PSInSAR approach described in (Hooper et al., 2004) to select PS candidates is applied because most persistent scatterers corresponding to houses, tall buildings and infrastructure works, located in the crowded residential areas of the urban districts and the villages in suburban districts can be easily identified. Locations without stable scatterers correspond to the water bodies or agricultural fields surrounding urban areas. From that, the signal of deformation from persistent pixels over time is separated to increase the number of observation samples and to assist the phase unwrapping process. To date, many studies have used this PSInSAR approach to apply to many types of SAR images for monitoring land subsidence in urban areas, such as (Cian et al., 2019).

\subsection{Data used}

\subsubsection{SAR dataset}

A dataset of 21 radar images acquired in the period from February 2007 to February 2011 by the PALSAR sensor ( $\mathrm{L}$ band, wavelength=23.6 cm) installed on the Japanese ALOS-1 satellite with ascending orbit is used for land subsidence estimation during the first stage. Another dataset of 51 radar images acquired in the period from April 2016 to September 2019 by the SAR sensor $(\mathrm{C}$ band, wavelength $=5.6 \mathrm{~cm}$ ) installed on the European Sentinel-1 satellite with descending orbit is used for land subsidence estimation during the second stage. The footprint of the ALOS-1 and Sentinel-1 scenes is presented in Figure 1 and shows that the two datasets cover the central urban region of Hanoi city. However, to estimate the evolution of land subsidence in the central urban region, a square study area with a size of $40 \times 40 \mathrm{~km}^{2}$ around it is delimited.

\subsubsection{Master image Selection}

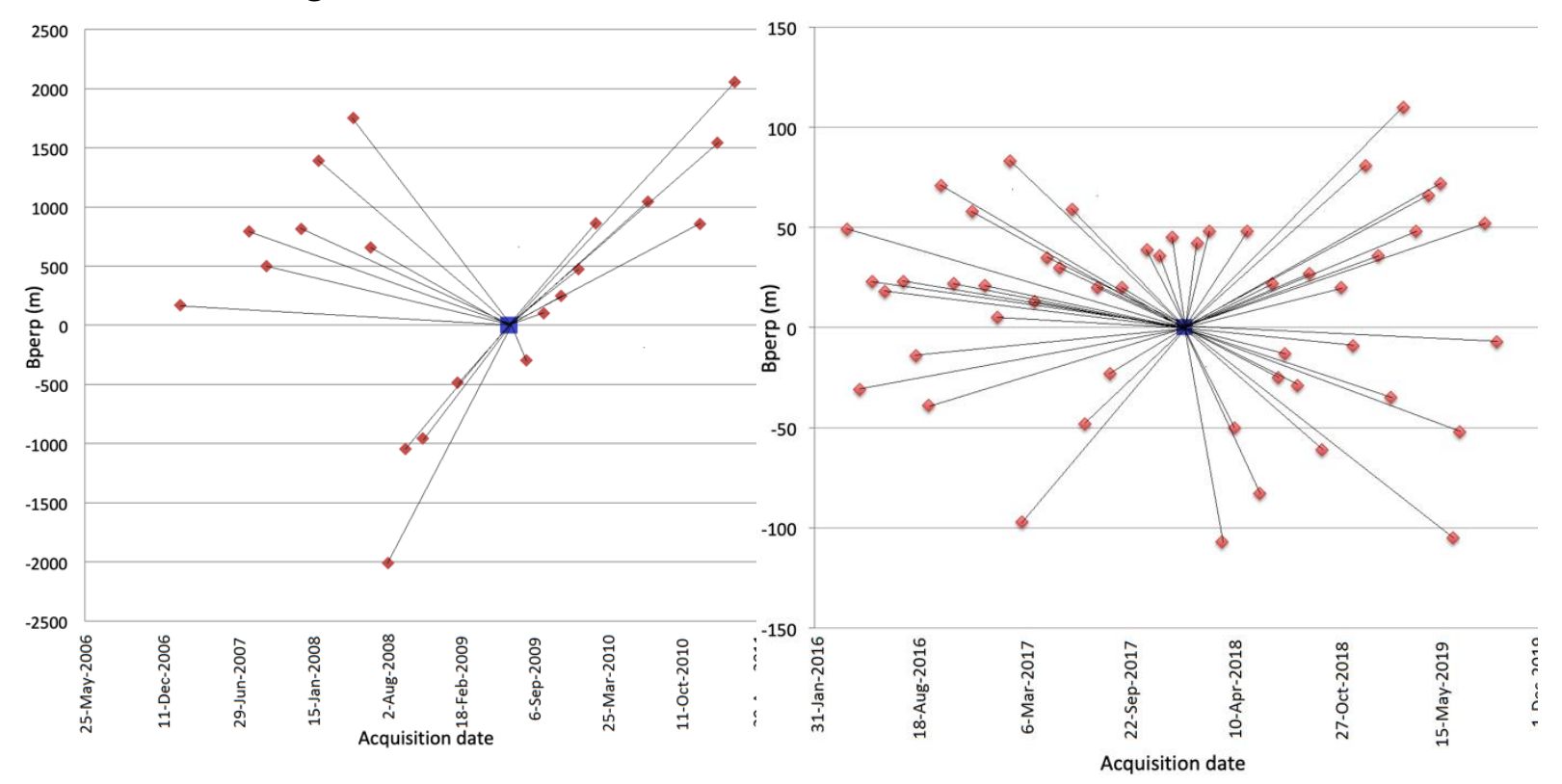

(a)

(b)

Figure 2 Baseline plot for the PSInSAR approach: The perpendicular baseline (Bperp) is calculated with respect to the master images (acquired dates: (a) 25 June 2009 for the period from 2/2007 to 2/2011 and (b) 11 January 2018) for the period from 4/2016 to 9/2019)

In the PSInSAR approach, master image selection is very important. The spatial baseline needs to be smaller than the critical values for each satellite type, and the temporal baseline is 
the average value between the images to minimize the temporal and spatial decorrelation. The perpendicular baseline between SAR images was calculated. The master image needs to be chosen as the most acceptable perpendicular baseline as possible. For the period from February 2007 to February 2011, the selected master image is from June 25, 2009. There are 20 interferograms calculated corresponding to the master image. For the period from April 2016 to September 2019, the selected master image is from January 11, 2018, and there are 50 interferograms created corresponding to the master image (Figure 2).

\subsubsection{Data Processing}

To eliminate the topography-related term from the interferogram, we use the global digital elevation model ALOS v.1 with a resolution of $30 \mathrm{~m}$ per pixel. Otherwise, the orbital-related term is removed from the interferogram using precise orbital data provided by JAXA and ESA.

\section{RESULTS AND DISCUSSION}

\subsection{Spatial Distribution of Land Subsidence}

Using the multitemporal data analysis method, a large number of persistent scatterers were selected in the study area for the two mentioned periods. To facilitate the visual comparison of the results of land subsidence in two periods, a uniform color scheme that assigns the subsidence velocity values is applied: red corresponds to $-50 \mathrm{~mm}$, and blue corresponds to $+50 \mathrm{~mm}$; the values in the middle correspond to the intermediate colors (color scale, refer to Figure 3).

\subsubsection{General Characters}

The heterogeneity of the subsidence velocity in the central urban region of Hanoi city during a period of approximately 4 years of study in both periods is shown in Figure 3. First, the deformation is concentrated mainly in the central urban region because it is reflected through persistent scatterers related to man-made structures. The average LOS velocity shows a clear difference between the northern and southern banks of the Red River. In general, on the northern bank of the Red River, the ground in both periods is stable; however some local subsidence locations can still be recognized east of the Dong Anh district and in the area between the Red and Duong Rivers, such as in the Long Bien district center or southwest of the Gia Lam district (Figure 3). These local subsidence locations have horizontal dimensions not exceeding $1-2 \mathrm{~km}^{2}$, and the maximum average LOS velocity is $15 \mathrm{~mm} / \mathrm{year}$. On the southern bank of the Red River, it can be seen that in the northern area along the Red River, corresponding to the districts of Tay Ho, Ba Dinh, Cau Giay and Bac Tu Liem, the ground is quite stable, and land subsidence occurs at an insignificant LOS velocity in both periods.

\subsubsection{Spatial Land Subsidence in the Period 2007-2011}

South of the Red River, the progress of land subsidence has changed significantly in the main subsidence areas in south, southwest and west of the central districts (Figures 3a and 3b). In the first period, the largest subsidence area corresponds to the Hoang Mai district located in south of the city center. The deformation corresponds to an average LOS velocity ranging from 5-35 mm/year and covering an area of $5 \times 5 \mathrm{~km}^{2}$, and it is surrounded in the north by a very rapid gradient of LOS velocity (Figures $3 \mathrm{a}$ and $4 \mathrm{a}$ ). The maximum average LOS velocity is located in this subsidence area and is only $1 \mathrm{~km}$ from the stable region. We recognize two large deformation locations with a size of $2 \times 2 \mathrm{~km}^{2}$ in the main subsidence area and some subsidence locations with dimensions not exceeding $0.5 \times 0.5 \mathrm{~km}^{2}$ and the LOS velocity can be up to $45 \mathrm{~mm} /$ year east of this subsidence area.

The second subsidence area is located in the Ha Dong - Thanh Xuan districts southwest of the city center (Figures $3 a$ and $4 b$ ). The horizontal dimension of this settlement area is very 
large, up to $7 \times 4 \mathrm{~km}^{2}$ but few locations in this area show LOS velocities in excess of 30 $\mathrm{mm} /$ year. We only realized a small location at a LOS velocity of $40 \mathrm{~mm} / \mathrm{year}$ in the south.

West of the central urban region, the third main subsidence area appears to be faintly visible due to the dispersion of scatterers in the Nam Tu Liem - Hoai Duc districts, where agricultural fields still dominate (Figures $3 \mathrm{a}$ and $4 \mathrm{c}$ ). Subsidence locations cover an area of $8 \times 3 \mathrm{~km}^{2}$ extending from south to north, where the LOS velocity varies from $5-25 \mathrm{~mm} /$ year.

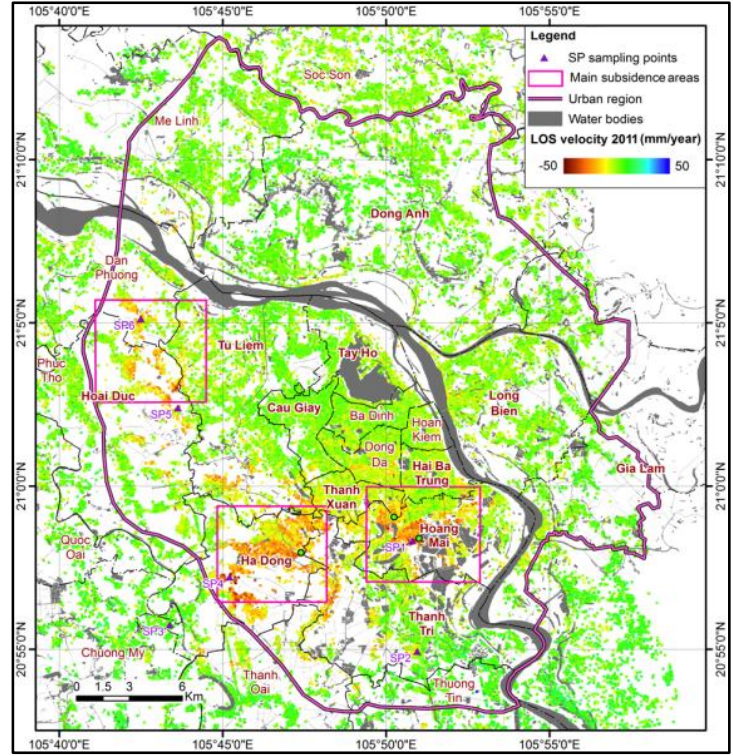

(a)

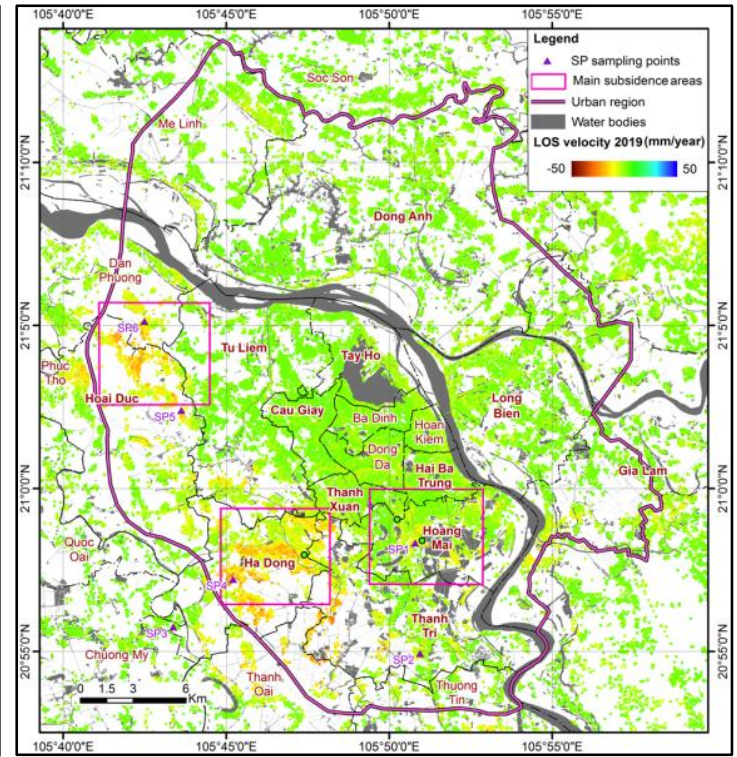

(b)

Figure 3 Average LOS velocity in the central urban region of Hanoi (location in Figure 1) issued from PSInSAR (a) for the period from 02/2007 to 02/2011 and (b) for the period from 4/2016 to 9/2019. Magenta boxes are the locations of Figures 4a, 4b, 4c, 4d, 4e, and 4f.

In many other parts of the city center, some subsidence locations with sizes of less than 1 $\mathrm{km}^{2}$ are distributed in the Dong Da, Ba Dinh, Thanh Xuan, and Hai Ba Trung districts with LOS velocities varying from $10-15 \mathrm{~mm} /$ year, which are much smaller than those of the three main subsidence areas described above.

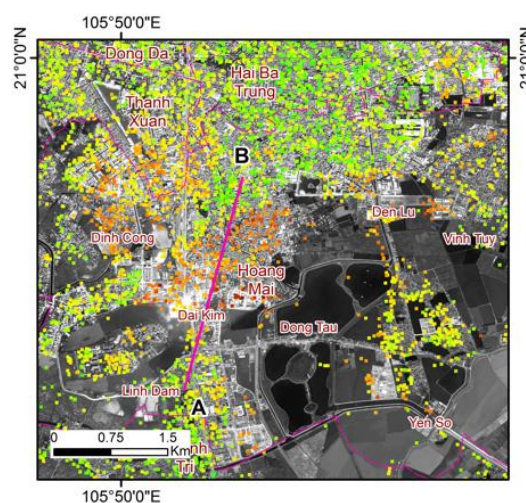

$105^{\circ} 50^{\circ} 0^{\circ} \mathrm{E}$

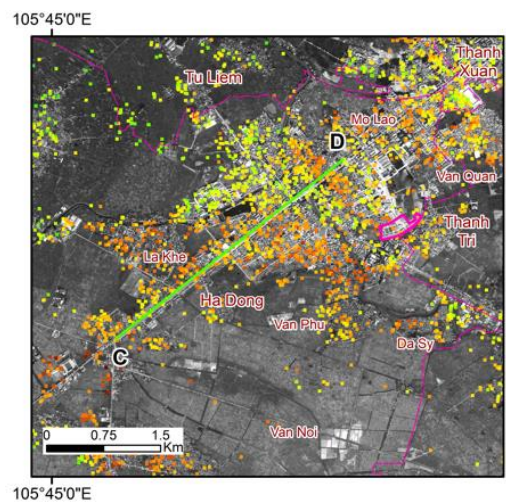

$105^{\circ} 45^{\prime} 0^{\prime \prime} \mathrm{E}$

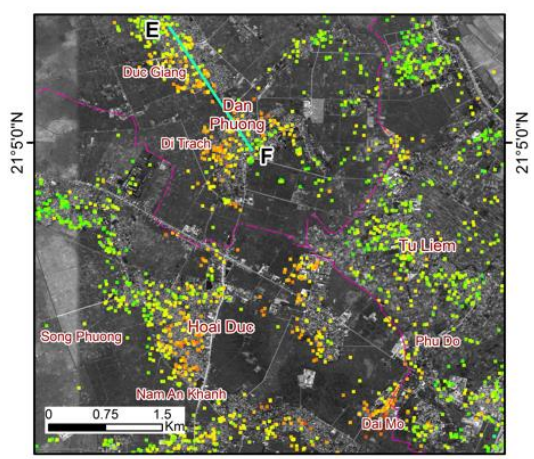




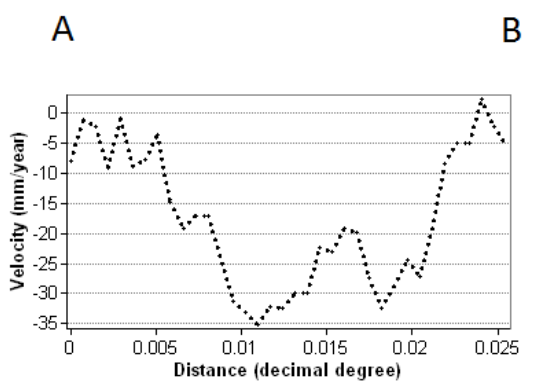

(a)

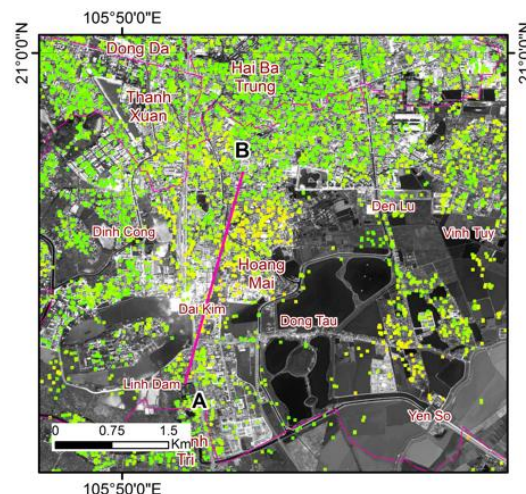

A

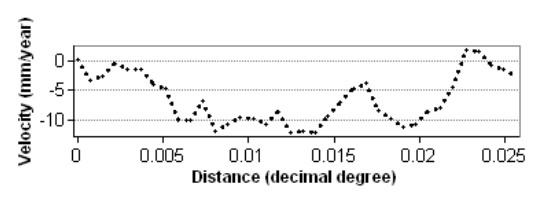

(d)
B C

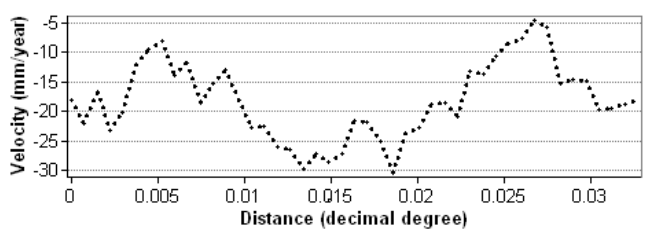

(b)

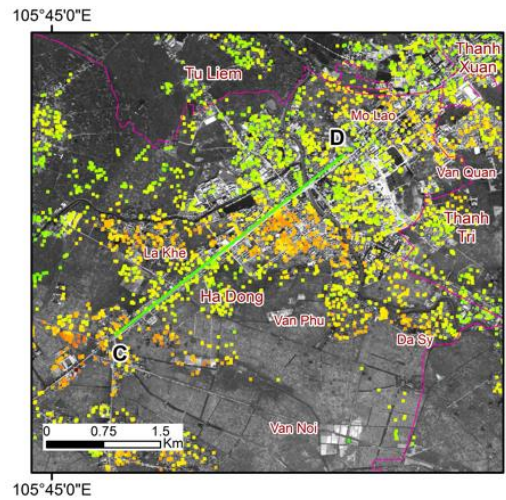

B

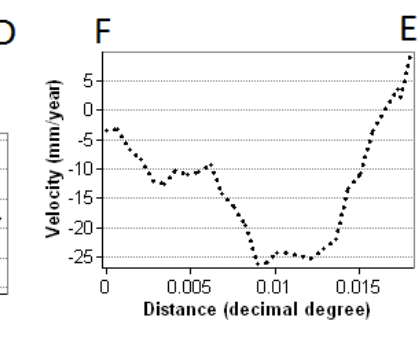

(c)

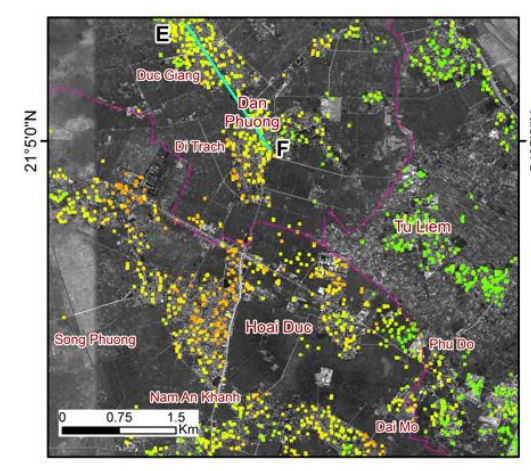

D $\mathrm{F}$

E

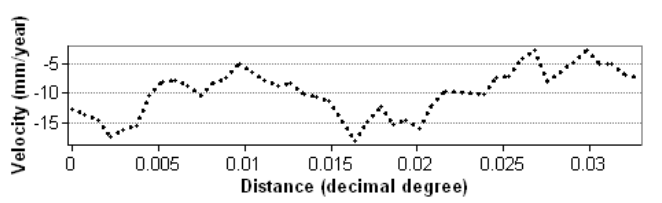

(e)

(f)

Figure 4 Close-up maps of LOS velocity for 2 periods: from 2/2007 to 2/2011 (upper) and from 4/2016 to 9/2019 (lower) with QuickBird image in the background at (a, d) Hoang Mai area, (b, e) Ha Dong - Thanh Xuan area (magenta boundary presents monitoring subsidence by leveling at Van Quan residential zone), and (c, f) Hoai Duc - Tu Liem area. For the location of the frame and color scale, refer to Figure 3

\subsubsection{Spatial Land Subsidence in the Period 2016-2019}

In the second period, the land subsidence area in the Hoang Mai district is narrowed in size and has a low average LOS velocity (Figures $3 b$ and $4 d$ ). Since only one subsidence location with an average LOS velocity ranging from 0-10 mm/year and covering the area of $1 \times 1 \mathrm{~km}^{2}$ is recognized, the land subsidence almost disappeared in the Hoang Mai area.

In the second subsidence area in the Ha Dong - Thanh Xuan districts, the average velocity tends to decrease to only $5-17 \mathrm{~mm} /$ year, but its spatial distribution extends to the south in the Thanh Oai district (Figures $3 b$ and $4 e$ ).

In the third subsidence area in the Nam Tu Liem - Hoai Duc districts, subsidence locations have spread to the west of the Phuc Tho district, but the average LOS velocity has decreased similarly to that in the second subsidence area, only reaching 3-12 mm/year (Figures $3 \mathrm{~b}$ and 4f).

In the central districts such as Dong Da, Ba Dinh, Thanh Xuan, and Hai Ba Trung, land subsidence has narrowed considerably compared to that in the previous period. Sunsidence is only very faintly expressed through small locations with an average LOS velocity ranging from 3-7 mm/year. 


\subsection{Validation}

To validate the accuracy of the results obtained from the InSAR method, the subsidence LOS velocity is converted into the vertical subsidence velocity with the incident angle $(\theta)$ for each pixel (average $\theta=38^{\circ}$ for the ALOS image) (Ng et al., 2011).

Then, the vertical subsidence velocity obtained by the PSInSAR method in the period of February 2007- February 2011 is compared to the subsidence velocity measured by the leveling method in the Van Quan new residential zone in the second main subsidence area of the Ha Dong - Thanh Xuan districts (location in Figure 3b). This area is the place where Hanoi Housing and Urban Development Corporation has implemented 16 cycles of the height observation of blocks using the leveling method from June 25, 2007 to September 26, 2008.

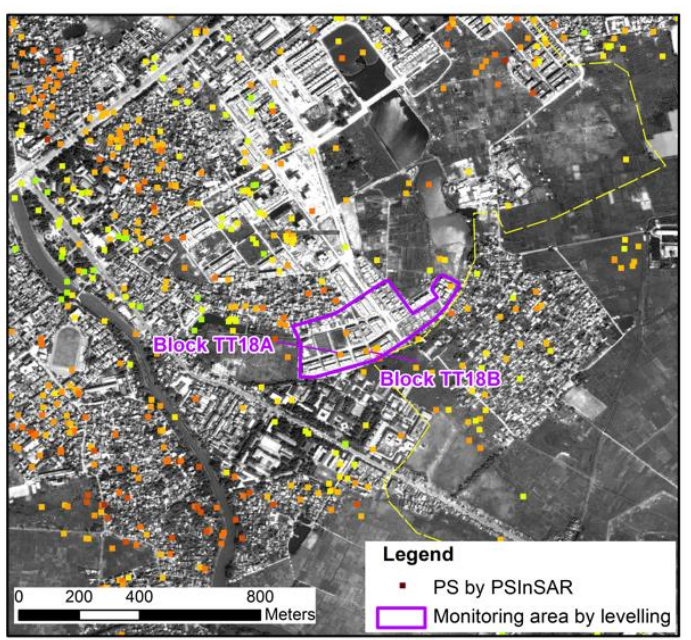

(a)

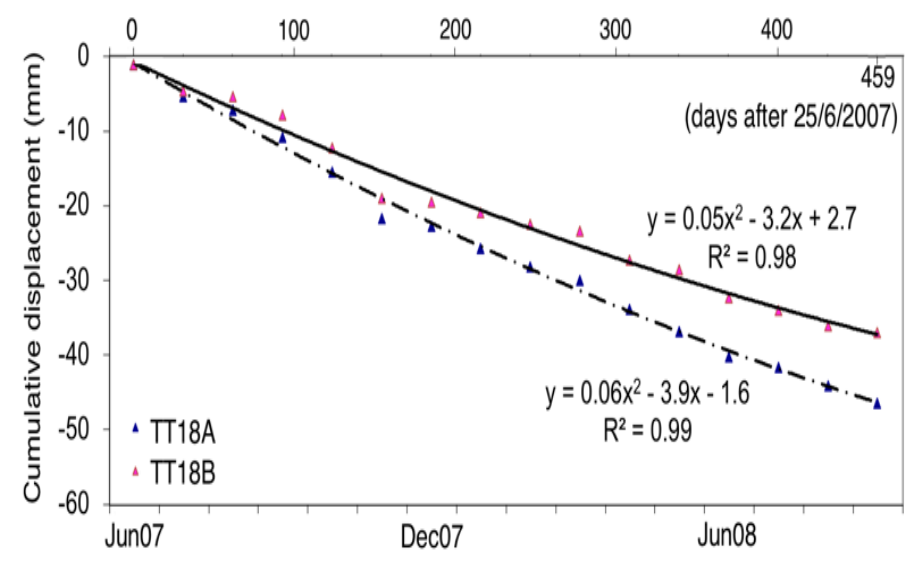

(b)

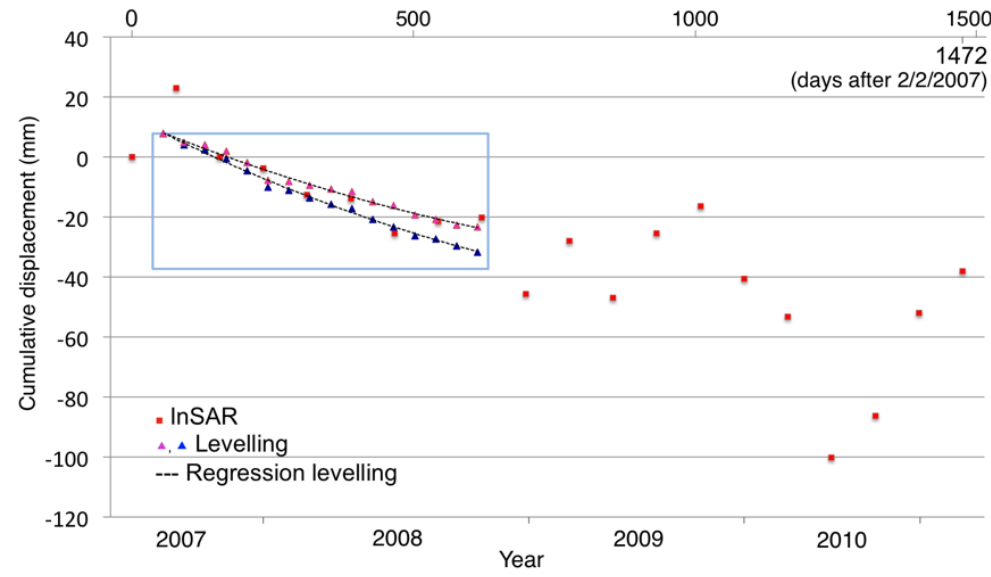

(c)

Figure 5 (a) Monitored area by the leveling method in Van Quan residential zone (PS points by PSInSAR drafted on QuickBird image). For location of the monitored area by leveling, refer to Figure $4 \mathrm{~b}$, and for PS points in the area (color scale) refer to Figure 3. (b) Leveling subsidence graph of blocks TT18A, and TT18B (Dinh et al., 2008). (c) Graphs of PS points located at blocks TT18A, and TT18B and leveling measurements. To adjust one set of data to the other set, the regression line of the leveling data are drafted arbitrarily through the points of the InSAR time series (Dang et al., 2013).

The height measurement data of the TT18A and TT18B building blocks is focused on due to the existence of fixed scattering points on these blocks (Figure 5a). The average subsidence 
velocity is derived from the height measurement data corresponding to the average subsidence velocity of $35 \mathrm{~mm} /$ year for the TT18A block and $27.8 \mathrm{~mm} / \mathrm{year}$ for the TT18B building block (Figure 5b). These averages are consistent with our InSAR processed results of $38.2 \mathrm{~mm} /$ year and $25.6 \mathrm{~mm} /$ year for the fixed scattering points located on the respective building blocks. A significant similarity exists between the land subsidence data obtained from the InSAR method and that from the leveling data in the period of June 2007 to September 2008. In this period, both subsidence datasets do not follow linear functions, consistent with constant velocity, but plot a quadratic polynomial function. As such, it shows a slow decline in the subsidence velocity vertically over time and shows the dynamics of the soil layer under reduced pore pressure due to groundwater intake. Therefore, except for the large noise contained in the data for the period after September 2008, the subsidence signal was clearly unstable but included shifts (Figure 5c). This outcome is very important because it shows the reliability of the settlement results received from the InSAR method.

In addition, during the period of 2011-2012, and 2018-2019, field trips were conducted to collate the results by the InSAR method with reality. In some new residential zones such as Dong Tau, Dai Kim, Den Lu (Hoang Mai district), Van Phu (Ha Dong district), Kim Chung and Di Trach (Hoai Duc district), much damage was recognized at the foundation of buildings or houses. For instance, a picture was taken on September $21^{\text {st }}, 2011$, showing that the steps of the N7 building of the Dong Tau residential zone were slanted due to land subsidence (Figure 6a). On December $10^{\text {th }}, 2019$, the householder acknowledged that the above steps were repaired in 2016, becoming a small green garden along the foundation of the building. However, 3 years after the repair, the steps stood horizontally with some cracks and these cracks had just been grouted before our visit (Figure 6b). This fact proves that land subsidence is still occurring in the first main subsidence area in the Hoang Mai district, but its impact has decreased in intensity during recent years.

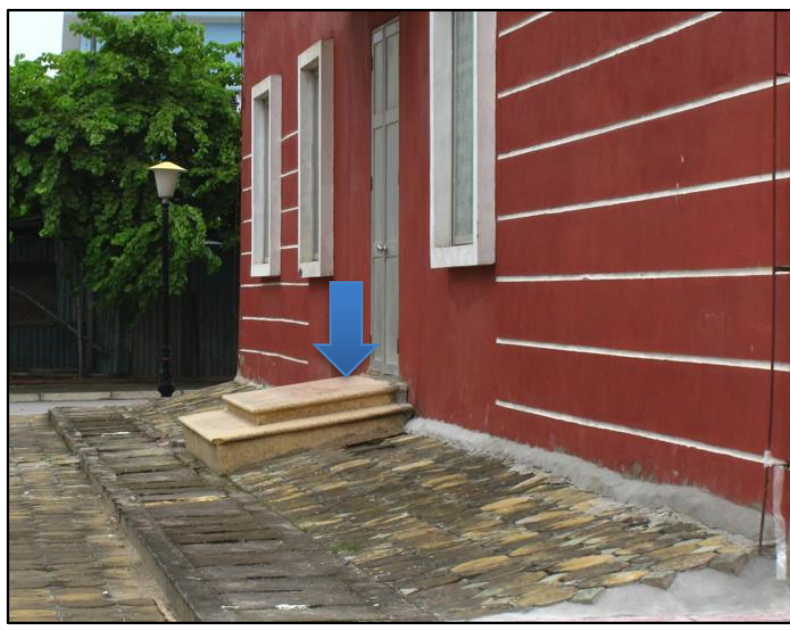

(a)

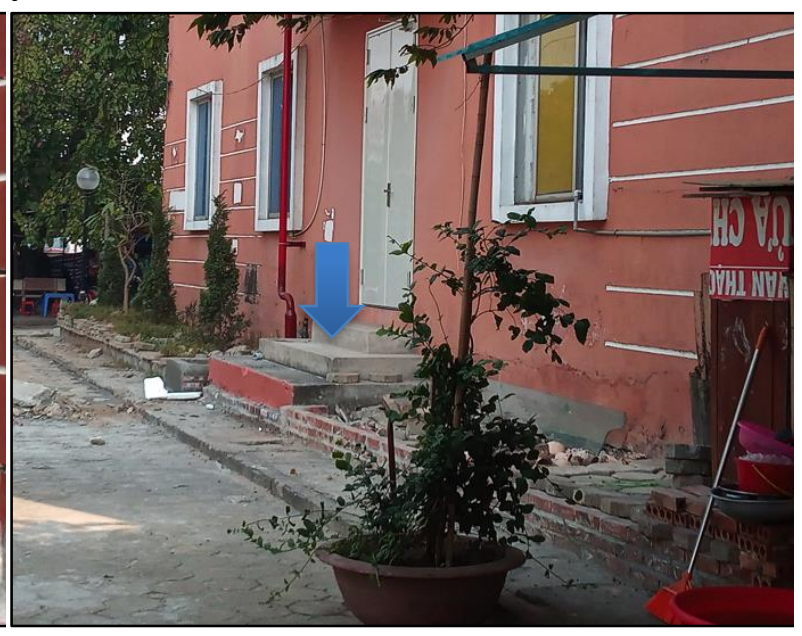

(b)

Figure 6 Damage at the first floor of building N7 in the Dong Tau new residential zone (Hoang Mai district) (a) on 21 September 2011, and (b) on 10 December 2019.

\section{CONCLUSIONS}

In recent years, the urbanization process has promoted urban expansion and infrastructure development with many construction projects around the central urban region of Hanoi city. Appropriate methods for monitoring geohazards in this new urban region are essential for managers. InSAR techniques for monitoring land subsidence appear competitive in 
comparison with traditional in situ measurement techniques in terms of time and cost due to the improvement in algorithms as well as the free and open data available. The multitemporal data analysis approach provides complete spatial coverage of the study area and overcomes the challenge of decorrelation in the tropical regions such as Hanoi. Consequently, the maps of the average LOS velocity established for the periods 2007-2011 and 2016-2019 can be used to monitor the subsidence evolution in the central urban region of Hanoi city, especially in the largest deformed areas corresponding to three areas in the Hoang Mai, Ha Dong Thanh Xuan and Hoai Duc - Tu Liem districts. The results show that the importance of the largest subsidence area in the Hoang Mai district was minimized in the second period. However, land subsidence continues to expand in the second and third subsidence areas, but its LOS velocity decreased significantly in the second period. This research determines that the multitemporal data analysis approach is effective for areas such as urban environments where man-made buildings are dominant.

\section{ACKNOWLEDGEMENT}

This study was conducted under the project VT-UD.12/17-20 funded by the Space Science and Technology Program. The authors would like to acknowledge the support of the European Space Agency (ESA) for providing Sentinel 1 SAR imagery.

\section{REFERENCES}

[1] Amelung, F., Galloway, D., Bell, J., Zebker, H., and R. Laczniak, 1999, Sensing the ups and downs of Las Vegas: InSAR reveals structural control of land subsidence and aquifersystem: Geology, v. 27, no. 6, pp. 483-486.

[2] Bitelli, G., and Russo, P., 1991, Levelling data management for the monitoring of land subsidence, in Proceedings Proceedings of Fourth International Symposium on Land Subsidence, Houston, USA, 12-17 May 1991, Volume 200: Oxfordshire, IAHS Publication, pp. 453-462.

[3] Brambati, A., Carbognin, L., Quaia, T., Teatini, P., and Tosi, L., 2003, The Lagoon of Venice: geological setting, evolution and land subsidence: Episodes, v. 26, no. 3, pp. 264268.

[4] Carnec, C., and Raucoules, D., 2001, Spécificite du milieu urbain tropical pour la cartographie des deformations de surface par interferometrie RADAR (ERS) - Application au pompage dans les systemes aquiferes a Djakarta et Hanoi: Bulletin - Société française de photogrammétrie et de télédétection, v. 161, no. 1, pp. 40-45.

[5] Cian, F., Blasco, J. M. D., and Carrera, L., 2019, Sentinel-1 for Monitoring Land Subsidence of Coastal Cities in Africa Using PSInSAR: A Methodology Based on the Integration of SNAP and StaMPS: Geoscience v. 9, no. 3.

[6] Crosetto, M., Monserrat, O., Cuevas-González, M., Devanthéry, N., and Crippa, B., Analysis of X-band very high resolution Persistent Scatterer Interferometry data over urban area, in Proceedings International Archives of the Photogrammetry, Remote Sensing and Spatial Information Science, Hannover, Germany, 21 - 24 May 2013 2013, Volume XL-1/W1, pp. 47-51.

[7] Dang, V. K., Doubre, C., Weber, C., Masson, F., and Gourmelen, N., 2013, Recent Land Subsidence Caused by the Rapid Urban Development in the Hanoi Urban Region (Vietnam) Using ALOS InSAR Data: Natural Hazard and Earth System Sciences, v. 14, no. 3, pp. 657-674.

[8] Dinh, V. X., Hoang, A. T., Cu, T. H., and Hoang, M. T., 2008, Report on measurement of new building in Van Quan ward-Hatay province: HUD-CIC Construction and Investment Consultants Joint Stock Company. 
[9] Froese, C. R., and Mei, S., 2008, Mapping and monitoring coal mine subsidence using LiDAR and InSAR, in Proceedings GeoEdmonton'08: 61st Canadian Geotechnical Conference, Edmonton, Canada, 21-24 September 2008, Canadian Geotechnical Society, pp. 1127-1133.

[10] Galloway, D. L., Hudnut, K. W., Ingebritsen, S. E., Phillips, S. P., Peltzer, G., Rogez, F., and Rosen4, P. A., 1998, Detection of aquifer system compaction and land subsidence using interferometric synthetic aperture radar, Antelope Valley, Mojave Desert, California: Water Resour Research, v. 34, no. 10, pp. 2573-2585.

[11] GSO, 2018, Ha Noi Statistical Yearbook 2017: Ha Noi, Statistic Publishing House.

[12] Hooper, A., Zebker, H., Segall, P., and Kampes, B., 2004, A new method for measuring deformation on volcanoes and other natural terrains using InSAR persistent scatterers: Geophysical Research Letters, v. 31, pp. L23611.

[13] Ikehara, M. E., 1994, Global Positioning System surveying to monitor land subsidence in Sacramento Valley, California, USA: Journal des Sciences Hydrologiques, v. 39, no. 5, pp. 417-430.

[14] Jusseret, S., Baeteman, C., and Dassargues, A., 2010, The stratigraphical architecture of the quaternary deposits as support for hydrogeological modelling of the central zone of Hanoi: Geologica Belgica, v. 13, no. 1-2, pp. 77-90.

[15] Lin, H., Chen, F., and Zhao, Q., 2011, Land deformation monitoring using coherent target-neighbourhood networking method combined with polarimetric information: a case study of Shanghai, China: International Journal of Remote Sensing, v. 32, no. 9, pp. 23952407.

[16] Massonnet, D., and Feigl, K. L., 1998, Radar interferometry and its application to changes in the Earth's surface: Reviews of Geophysics, v. 36, no. 4, pp. 441-500.

[17] Montangero, A., Cau, L. N., Anh, N. V., Tuan, V. D., Nga, P. T., and Belevi, H., 2007, Optimising water and phosphorus management in the urban environmental sanitation system of Hanoi, Vietnam: Science of The Total Environment, v. 384, no. 1-3, pp. 55-66.

[18] Ng, A. H., Ge, L., Zhang, K., Chang, H., Li, X., Rizos, C., and Omura, M., 2011, Deformation mapping in three dimensions for underground mining using InSAR Southern highland coal field in New South Wales, Australia: International Journal of Remote Sensing, v. 32, pp. 7227-7256.

[19] Nguyen, N. M., 2007, Review and analysis of Hanoi land subsidence monitoring data: [M.Sc: Asian Institute of Technology, 140 p.

[20] Nguyen, Q. T., and Helm, D. C., 1995, Land subsidence due to groundwater withdrawal in Hanoi, Vietnam in Proceedings Fifth International Symposium on Land Subsidence, Hague, The Netherlands, 16-20 October 1995, Volume 234: Oxfordshire, IAHS Publication, pp. 55-60.

[21] Noel, A., 2008, Apport de l'interférométrie radar dans la gestion des risques naturels: Cas de Hanoi, Vietnam: [Master: Université de Liège, 106 p.

[22] Peltzer, G., Crampé, F., Hensley, S., and Rosen, P., 2001, Transient strain accumulation and fault interaction in the Eastern California shear zone: Geology, v. 29, no. 11, pp. 975978.

[23] Phien-wej, N., Giao, P. H., and Nutalaya, P., 2006, Land subsidence in Bangkok, Thailand: Engineering Geology, v. 82, no. 4, pp. 187-201.

[24] Poland, J. F., 1984, Guidebook to studies of land subsidence due to groundwater withdrawal: Paris, Unesco, 323 p. 
[25] PPJ, VIAP, and HUPI, 2011, Hanoi Master Plan to 2030 and vision to 2050: Ha Noi's Department of Planning and Architecture, 196 p.

[26] Raucoules, D., and Carnec, C., DEM derivation and subsidence detection on Hanoi from ERS SAR, in Proceedings FRINGE99- Advancing ERS SAR Interferometry from applications towards operations, Liege, Belgium, 10-12 November 1999 1999, ESA Publications Division, pp. on CDROM.

[27] Solari, L., Soldato, M. D., Bianchini, S., Ciampalini, A., Ezquerro, P., Montalti, R., Raspini, F., and Morett, S., 2018, From ERS 1/2 to Sentinel-1: Subsidence Monitoring in Italy in the Last Two Decades: Frontier in Earth Science, v. 16, no. 149.

[28] Tran, T. V. N., Application of dynamic system for sustainable urban water supply: A case study in Hanoi city, in Proceedings The 15th Stockholm Water Symposium, Stockholm, 2005, Stockholm International Water Institute.

[29] Tran, V. A., 2007, Synthetic aperture radar interferometry for DEM generation and subsidence detection over Hanoi city, Vietnam: Docteur Thesis: University of Osaka, 102 p.

[30] Trinh, M. T., and Fredlund, D. G., 2000, Modelling subsidence in the Hanoi city area: Canadian geotechnical journal v. 37, no. 3, pp. 621-636.

[31] Vöge, M., 2011, Subsidence Estimation Over the City of Hanoi using SAR Interferometry: NGI, $65 \mathrm{p}$.

[32] Waltham, T., 2014, Ground subsidence in Mexico City: Mercian Geologist, v. 18, no. 3, pp. 194-195. 